\title{
Water Activity and Freezing Points in Aqueous Solutions of Manganese Nitrate: Experimental and Modeling
}

\author{
Mouad Arrad ${ }^{1,2} \cdot$ Mehriban Aliyeva $^{3}$ - Sérgio M. Vilas-Boas ${ }^{3} \cdot$ \\ Mohammed Kaddami ${ }^{2}$ Hannu Sippola ${ }^{4,5} \cdot$ Pekka Taskinen $^{4} \cdot$ \\ Simão P. Pinho ${ }^{3,6}$ (D)
}

Received: 8 November 2017/Accepted: 7 February 2018/Published online: 19 April 2018

(C) Springer Science+Business Media, LLC, part of Springer Nature 2018

\begin{abstract}
The water activities of manganese nitrate solutions were measured using a humidity sensor instrument up to almost the saturation molality at $298.15 \mathrm{~K}$; the thermodynamic properties of the system were described by the Pitzer model and specific interaction theory (SIT). The evaluation of the ion interaction parameters for the Pitzer model and SIT were carried out using experimental freezing points and osmotic coefficients of manganese nitrate aqueous solutions, collected from the open literature, and the water activity data measured in this work. A set of Pitzer and SIT parameters were estimated using a temperature dependency, that enables us to cover wider temperature ranges, and consequently calculate system properties to higher molalities. Both approaches represent very satisfactorily, and with similar accuracy, the experimental data and the calculated manganese nitrate molal activity coefficients are comparable to those already published for analogous systems. Additionally, the Pitzer model was also able to calculate the ice curve and the solubility branch of manganese nitrate hexahydrate up to a salt solution $6.5 \mathrm{~mol} \cdot \mathrm{kg}^{-1}$.
\end{abstract}

Keywords Osmotic coefficient $\cdot$ Freezing points $\cdot$ Pitzer $\cdot$ SIT $\cdot$ Solubility

Simão P. Pinho

spinho@ipb.pt

1 Department of Process Engineering, National School of Mines of Rabat, BP 753 Agdal, Rabat, Morocco

2 LaboratoryPhysical Chemistry of Processes and Materials, Faculty of Science and Technology, University Hassan 1, Settat, Morocco

3 Associate Laboratory LSRE-LCM, Departamento de Tecnologia Química e Biológica, Instituto Politécnico de Bragança, Bragança, Portugal

4 Department of Chemical and Metallurgical Engineering, Metallurgical Thermodynamics and Modeling, Aalto University School of Chemical Engineering, Aalto, Finland

$5 \quad$ FCG Design and Engineering, Osmontie 34, 00601 Helsinki, Finland

6 Centro de Investigação de Montanha CIMO, Instituto Politécnico de Bragança, Campus de Santa Apolónia, Bragança, Portugal 


\section{Introduction}

The development of science and technology requires accurate data concerning the thermodynamic properties and phase equilibria, but also robust models to extend their usefulness. In particular, in electrolyte solution thermodynamics, concepts such as standard states and activity coefficients in different concentration scales are rather complex, or ambiguous, leading to several difficulties and inaccuracies. The need to define mean ionic properties and deal with the speciation, adds more obstacles in the search for those models. As a component of the vast electrolyte field, the measurement and calculation of the activity coefficient of salts dissolved in water is not an easy task but some studies were carried out in the past to correlate and predict the activity coefficients using several models [1-5]. Even when a sufficient amount of experimental data is available, the ability of a model to accurately represent the thermodynamic properties and its extrapolation capability are still big challenges to overcome. Molecular simulation is starting to be an alternative way to model electrolyte solutions [6,7] and a recent study by May and Rowland [8], gives a critical review on the subject.

The studied system in this work is one of the "forgotten" systems, since only a very few experimental data are available. However, manganese nitrate, as well as other metal nitrate salts, is used in several industrial applications such as precursors in ferrite and nanocomposite technologies, and production of ceramics and catalysts [9]. It can also be used to correct manganese deficiencies in agriculture. For these reasons, a new set of water activity data was measured, starting from low molality up to near the saturation limit at $298.15 \mathrm{~K}$.

For modeling purposes, we first applied the Pitzer formalism, which is one of the most frequently used and successful models for electrolyte solutions, with well established parameters for a large number of aqueous binary electrolyte solutions. The model is well known for its capacity to correlate strong electrolyte solutions and to describe different solution properties and phase equilibria, including: osmotic coefficients, activity coefficients, Gibbs energy and the solubility product. Sadowska and Libuś [10] have modeled the osmotic coefficient of manganese nitrate at $298.15 \mathrm{~K}$ using the Pitzer model and a fifth order polynomial. They concluded that their Pitzer parameters were applicable only below a molal concentration of $1.8 \mathrm{~mol} \cdot \mathrm{kg}^{-1}$ of solvent but the polynomial expression could correlate their experimental data for the whole experimental molality range up to $5.6 \mathrm{~mol} \cdot \mathrm{kg}^{-1}$. For the calculation of activity coefficients at rounded molalities they used Pitzer's model up to 1.8 molal and the polynomial expression after that up to 5.5 molal. Recently the $\mathrm{Mn}\left(\mathrm{NO}_{3}\right)_{2}-\mathrm{H}_{2} \mathrm{O}$ system has also been modelled using UNIQUAC model [11], giving a good representation of the solubilities, but failing in the description of the osmotic and mean ionic molal activity coefficients.

The SIT (Specific Interaction Theory) model was also implemented for comparison purposes. This theory was formulated first by Ciavatta [12] in 1980 based on the earlier works of Brønsted [13], Guggenheim [14, 15] and Scatchard [16, 17]. This approach is widely used in geochemistry and hydrometallurgy for its simplicity and also the possibility to evaluate activity coefficients based only on the specific interaction of ions in the solution. An extensive review of this theory was given by Grenthe et al. [18].

This study presents the first set of parameters for the Pitzer and SIT models based on the available experimental data of manganese nitrate-water solutions [10, 11, 19-22]. In particular, the determination of the Pitzer parameters enables us to represent accurately the aqueous solution properties at low temperatures, from its very dilute region up to the saturation of the salt and even beyond, with the possibility of extrapolating the model to 
temperatures above $298.15 \mathrm{~K}$ and, also, the calculation of the ice curve and the solubility branch for manganese nitrate hexahydrate.

\section{Experimental}

\subsection{Chemicals}

Table 1 presents the source and purity of the substances used, as given by the supplier. No further purifications were carried out.

To avoid water contamination, $\mathrm{NaBr}$ was dried at $343.15 \mathrm{~K}$ and $\mathrm{LiCl}$ at $423.15 \mathrm{~K}$ in a drying stove for more than 2 days and cooled after in a dessicator with silica gel before use. The water content of the manganese nitrate was determined by Karl Fischer titration (Mettler Toledo DL32 Karl Fischer coulometer using the Hydranal-Coulomat E from Riedel-de Haen as analyte) and found to be $28.9 \%$ ( \pm 0.36 , at a $95 \%$ confidence interval) in mass percentage, corresponding to an hydration number close to 4.04. Doubly distilled water, passed through a reverse osmosis system and further treated with a Milli-Q plus 185 water purification equipment was used in all experiments.

\subsection{Procedure}

Approximately $60 \mathrm{~g}$ of manganese nitrate aqueous solution was first prepared by weighing into a balloon-flask the appropriate masses $( \pm 0.1 \mathrm{mg})$ of salt and water for the desired molality. The resulting solution was vigorously stirred to promote salt dissolution. Following, that solution was used to prepare, by dilution with water, about $10 \mathrm{~cm}^{3}$ of manganese nitrate solutions with the other desired molalities. Taking into consideration the uncertainty in the water mass percentage in the salt, as well as the balance inaccuracy, the final molality values have a precision $(\Delta m / m)$ better than 0.012 .

The measurements of water activities $\left(a_{\mathrm{w}}\right)$ were performed using a LabMaster- $\mathrm{a}_{\mathrm{w}}$ hygrometer (Novasina, Switzerland), already used by us in amino acid with electrolyte [23] and ionic liquid aqueous solutions [24]. For each measurement, samples of approximately $2-3 \mathrm{~cm}^{3}$ were charged in the measuring dishes and finally placed in the air-tight equilibrium chamber. The exchange of free water takes place until the partial pressure of water vapor reaches the equilibrium pressure, which is confirmed following the $a_{\mathrm{w}}$ variation with time. When a constant value is reached, the water activity is recorded. The uncertainty of the measurements is better than $0.002 a_{\mathrm{w}}$, enabling measurements under controlled chamber temperature conditions $( \pm 0.15 \mathrm{~K})$. To improve accuracy, each day that measurements were carried out, a calibration curve was also measured. At least four $\mathrm{NaBr}$ or $\mathrm{LiCl}$ aqueous solutions were prepared at distinct molalities, chosen based on the expected values

Table 1 Source and mass purity of the substances used

\begin{tabular}{lll}
\hline Compound & Source & Mass purity(\%) \\
\hline $\mathrm{Mn}\left(\mathrm{NO}_{3}\right)_{2} \cdot 4 \mathrm{H}_{2} \mathrm{O}$ & Alfa Aesar & 98 \\
$\mathrm{NaBr}$ & Agros & 99.5 \\
$\mathrm{LiCl}$ & Alfa Aesar & 99 \\
\hline
\end{tabular}


for the water activity to be measured along with the aqueous manganese nitrate solutions. The measured values were compared to those published in the literature for $\mathrm{LiCl}$ solutions by Hamer and $\mathrm{Wu}$ [25], and for $\mathrm{NaBr}$ solutions by Archer [26].

\subsection{Experimental Results}

The experimental water activity data as well as the osmotic coefficients measured in this work are presented in Table 2.

\section{Modeling}

\subsection{Review of Experimental Data}

To the best of our knowledge, the only experimental data available for the osmotic coefficients in aqueous solutions of manganese nitrate were published by Sadowska and Libuś [10]. These authors measured the osmotic coefficient at $298.15 \mathrm{~K}$ (up to 5.6 $\mathrm{mol} \cdot \mathrm{kg}^{-1}$ ) using the isopiestic method; these are in good agreement with the values here found, but present more evident deviations at higher molalities. We should also cite the earlier work from Ewing et al. [22], where the authors measured the vapor pressure of aqueous manganese nitrate solutions at several temperatures up to saturation. When the values are converted to osmotic coefficients there are evident deviations from the other two sets (see Fig. 1) and the data measured by Ewing et al. [22] were not considered for

Table 2 Water activity $\left(a_{\mathrm{w}}\right)$ and osmotic coefficients $(\phi)$ of manganese nitrate aqueous solutions at different salt molalities, $298.15 \mathrm{~K}$ and $p=0.1 \mathrm{MPa}$

\begin{tabular}{|c|c|c|c|}
\hline \multirow{3}{*}{$\begin{array}{l}\text { Table } 2 \text { Water activity }\left(a_{\mathrm{w}}\right) \text { and } \\
\text { osmotic coefficients }(\phi) \text { of man- } \\
\text { ganese nitrate aqueous solutions } \\
\text { at different salt molalities, } \\
298.15 \mathrm{~K} \text { and } p=0.1 \mathrm{MPa}\end{array}$} & $\mathrm{m}\left(\mathrm{mol} \cdot \mathrm{kg}^{-1}\right)$ & $a_{\mathrm{w}}$ & $\phi$ \\
\hline & 0.501 & 0.975 & 0.936 \\
\hline & 1.000 & 0.943 & 1.086 \\
\hline & 1.198 & 0.930 & 1.120 \\
\hline & 1.400 & 0.916 & 1.159 \\
\hline & 1.599 & 0.896 & 1.270 \\
\hline & 1.798 & 0.879 & 1.326 \\
\hline & 1.996 & 0.864 & 1.354 \\
\hline & 2.000 & 0.862 & 1.373 \\
\hline & 2.476 & 0.819 & 1.491 \\
\hline & 2.990 & 0.769 & 1.625 \\
\hline & 3.498 & 0.720 & 1.737 \\
\hline & 3.979 & 0.673 & 1.841 \\
\hline & 4.496 & 0.623 & 1.947 \\
\hline & 4.964 & 0.573 & 2.075 \\
\hline & 4.994 & 0.575 & 2.050 \\
\hline & 5.504 & 0.520 & 2.197 \\
\hline & 6.004 & 0.477 & 2.280 \\
\hline & 6.507 & 0.435 & 2.366 \\
\hline & 6.953 & 0.396 & 2.464 \\
\hline$u_{\mathrm{r}}(\Delta m / m)=0.012$ & 7.465 & 0.359 & 2.538 \\
\hline $\begin{array}{l}u\left(a_{\mathrm{w}}\right)=0.002, u(T)=0.15 \mathrm{~K} \\
u_{\mathrm{r}}(p)=0.05\end{array}$ & 7.943 & 0.326 & 2.610 \\
\hline
\end{tabular}


Fig. 1 Osmotic coefficient of manganese nitrate aqueous solutions at $298.15 \mathrm{~K}$ : comparison of the experimental data (dots) and those calculated by the Pitzer model (full line) and SIT (dashed line)

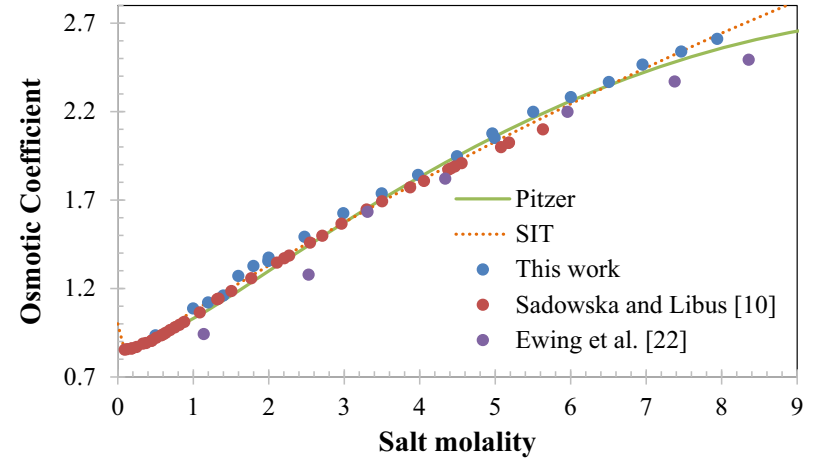

parameter estimation. Freezing point depression data were measured by two different experimental techniques, the lowering of freezing point and the conductometric method. Jones and Getman [27] measured those in manganese nitrate solutions at several concentrations, but Jones et al. [19] have found that their own previous values were not correct, so they proposed a revised set of experimental data, which is consistent with the recently published experimental data by Arrad et al. [11].

Regarding solubility, the work of Funk [21] is one of the oldest studies related to metal nitrate salts, and Ewing and Rasmussen [20] published the phase diagram of manganese nitrate salt at higher concentrations, presenting very large uncertainties at temperatures close to $298.15 \mathrm{~K}$ due to the transition of the solid phase in equilibrium with the saturated solution, from manganese nitrate hexahydrate to tetrahydrate. Table 3 summarizes the important information about the experimental data collected.

\subsection{Pitzer Model}

The Pitzer model [28] was used to fit the osmotic coefficients and to calculate the mean ionic molal activity coefficients of the electrolyte $\gamma_{ \pm}$. The expressions of the Pitzer model for a binary (i.e. salt-water) systems can be written as:

$$
\emptyset=1-A_{\phi} z_{\mathrm{M}}\left|z_{\mathrm{X}}\right|\left(\frac{\sqrt{I}}{1+b \sqrt{I}}\right)+2 m\left(\frac{v_{\mathrm{M}} v_{\mathrm{X}}}{v}\right) B_{\mathrm{MX}}^{\phi}+2 m^{2}\left[\frac{\left(v_{\mathrm{M}} v_{\mathrm{X}}\right)^{1.5}}{v}\right] C_{\mathrm{MX}}^{\phi}
$$

Table 3 Summary of the experimental data collected from the open literature

\begin{tabular}{lllll}
\hline Data type & Temperature (K) & Molality & Data points & Reference \\
\hline Osmotic-VLE & 298.15 & $0.09-5.63$ & 40 & Sadowska and Libuś [10] \\
Vapor pressure & $293.15-313.15$ & $1.14-22.81$ & 20 & Ewing et al. [22] \\
Freezing-SLE & $246.15-272.71$ & $0.09-3.08$ & 9 & Jones et al. [19] \\
Freezing-SLE & $244.15-265.65$ & $1.05-3.20$ & 6 & Arrad et al. [11] \\
Salt solubility & $244.15-308.65$ & $4.1-18.5$ & 11 & Funk [21] \\
Salt solubility & $273.15-353.15$ & $6.27-27.87$ & 41 & Ewing and Rasmussen [20] \\
Salt solubility & $244.15-309.15$ & $1-11.3$ & 9 & Arrad et al. [11] \\
\hline
\end{tabular}




$$
\ln \gamma_{ \pm}=z_{\mathrm{M}}\left|z_{\mathrm{X}}\right| f^{\gamma}+2 m\left(\frac{v_{\mathrm{M}} v_{\mathrm{X}}}{v}\right)\left(B_{\mathrm{MX}}^{\phi}+B_{\mathrm{MX}}\right)+3 m^{2}\left[\frac{\left(v_{\mathrm{M}} v_{\mathrm{X}}\right)^{1.5}}{v}\right] C_{\mathrm{MX}}^{\phi}
$$

where,

$$
\begin{gathered}
f^{\gamma}=-A_{\phi}\left[\frac{\sqrt{I}}{1+\mathrm{b} \sqrt{I}}+\frac{2}{\mathrm{~b}} \ln (1+\mathrm{b} \sqrt{I})\right] \\
B_{\mathrm{MX}}^{\phi}=\beta^{(0)}+\beta^{(1)} \exp \left(-\alpha_{1} \sqrt{I}\right)+\beta^{(2)} \exp \left(-\alpha_{2} \sqrt{I}\right) \\
B_{\mathrm{MX}}=\beta^{(0)}+\beta^{(1)} g\left(\alpha_{1} \sqrt{I}\right)+\beta^{(2)} g\left(\alpha_{2} \sqrt{I}\right)
\end{gathered}
$$

The function $g(x)$ in Eq. 5 is:

$$
g(x)=\frac{2\left[1-(1+x) \mathrm{e}^{-x}\right]}{x^{2}}
$$

In Eqs. 1 and 2, the symbols $z_{\mathrm{M}}$ and $z_{\mathrm{X}}$ are the electric charges of the cation (M) and anion $(\mathrm{X})$ in the electrolyte, $v_{\mathrm{M}}$ and $v_{\mathrm{X}}$ are the stoichiometric coefficients of the ions in the salt, with the notation $v=v_{\mathrm{M}}+v_{\mathrm{X}}$ and $I$ is the ionic strength of the solution. Its relation with the composition coordinate of the electrolyte solution expressed with molality $m_{i}$ is given as:

$$
I=\frac{1}{2} \sum_{i} m_{i} z_{i}^{2}
$$

where the summation is over all aqueous solute species and $z_{i}$ is the electric charge for species $i$. The parameters $B_{\mathrm{MX}}^{\phi}$ and $B_{\mathrm{MX}}$ represent the concentration dependence of the electrolyte specific terms in Eqs. 1 and 2, while $\alpha_{1}, \alpha_{2}, \beta^{(0)}, \beta^{(1)}, \beta^{(2)}$ and $C_{\mathrm{MX}}^{\phi}$ are the Pitzer parameters given in Eqs. 1, 2, 4 and 5.

Since we have only one electrolyte of the 2-1 type in our scrutiny, the parameters $\alpha_{2}$ and $\beta^{(2)}$ were considered zero in the Pitzer model. The internal parameters of the Pitzer model used in this work were $b=1.2\left(\mathrm{~kg} \cdot \mathrm{mol}^{-1}\right)^{1 / 2}, \alpha_{1}=2.0\left(\mathrm{~kg} \cdot \mathrm{mol}^{-1}\right)^{1 / 2}$; these are the original values proposed by Pitzer [28]. $A_{\phi}$ is the theoretical, limiting Debye-Hückel slope at infinite dilution, calculated according to the correlation given by Akinfiev et al. [29]. It reproduces the temperature variation of the Debye-Hückel term at low temperatures, from $233.15 \mathrm{~K}$ to room temperature.

\subsection{Specific Interaction Theory}

In the SIT approach, the expressions for the osmotic coefficient and the mean ionic molal activity coefficient for an aqueous binary solution containing the electrolyte MX are given as:

$$
\emptyset-1=-\frac{\left|Z_{\mathrm{M}} Z_{\mathrm{X}}\right| A_{\gamma}}{1.5^{3}}\left(t-2 \ln t-t^{-1}\right)+\frac{v_{\mathrm{M}} v_{\mathrm{X}}}{v} \varepsilon_{\gamma}(\mathrm{M}, \mathrm{X}) m
$$




$$
\ln \gamma_{ \pm}=-\frac{\left|Z_{\mathrm{M}} Z_{\mathrm{X}}\right| A_{\gamma} I^{1 / 2}}{t}+2 \frac{v_{\mathrm{M}} v_{\mathrm{X}}}{v} \varepsilon_{\gamma}(\mathrm{M}, \mathrm{X}) m
$$

where $t=1+1.5 \sqrt{I}, \varepsilon_{\gamma}(\mathrm{M}, \mathrm{X})$ is the specific interaction parameter, and $A_{\gamma}=3 A_{\phi}$.

Within SIT a constant term for the specific interaction parameters between the cation and the anion is generally used. However, in this work the salt molality can reach a value above 8 (ionic strength above 24), and to describe, with enough accuracy, the properties of the system, a concentration dependence on the interaction parameter was applied. Following the approach by Crea et al. [30] the proposed dependence is of the form:

$$
\varepsilon_{\gamma}(\mathrm{M}, \mathrm{X})=\varepsilon_{0 \gamma}(\mathrm{M}, \mathrm{X})+\varepsilon_{1 \gamma}(\mathrm{M}, \mathrm{X}) I
$$

where $\varepsilon_{0 \gamma}(\mathrm{M}, \mathrm{X})$ and $\varepsilon_{1 \gamma}(\mathrm{M}, \mathrm{X})$ are the parameters to be estimated from experimental data.

\subsection{Parameter Estimation}

The estimation of Pitzer and SIT parameters was carried out using an objective function $(O F)$ minimizing the square error between each experimental osmotic coefficient $\left(\phi_{\text {Exp }}\right)$ and that calculated $\left(\phi_{\text {Model }}\right)$ by the model, according to Eq. 11:

$$
O F=\sum_{i}\left(\phi_{\text {Model }, i}-\phi_{\operatorname{Exp}, i}\right)^{2}
$$

As is shown in Eq. 11, the objective function used in this study does not include any weighting factors. However, some data points, presenting large random deviations from the general trend were neglected in the parameter optimization. The use of freezing point data is very important to understand the behavior of the system at low temperatures. It also enables us to obtain the experimental osmotic coefficient at low temperatures, through water activity calculated by the solid-liquid equilibrium equation [31], making is possible to propose a more flexible and robust model.

The use of osmotic coefficient was the first step for estimating the model parameters, which will then be used for the determination of the solubility product of manganese nitrate hexahydrate, based on the available solubility data up to around 8 molal. In this study, a temperature dependency of the form $p=a+b / T$ was proposed for all the parameters to be estimated, that are $\beta^{(0)}, \beta^{(1)}$ and $C_{\mathrm{MX}}^{\phi}$ in the Pitzer model, and $\varepsilon_{0 \gamma}(\mathrm{M}, \mathrm{X})$ and $\varepsilon_{1 \gamma}(\mathrm{M}, \mathrm{X})$ in the SIT. Several combinations were tested to get the best representation of the osmotic coefficients, either from isopiestic, water activity or freezing depression data.

\section{Results and Discussion}

Table 4 shows the values of the estimated parameters and their corresponding values at 273.15 and $298.15 \mathrm{~K}$. From the estimated Pitzer parameters we observe $\beta^{(0)}$ changes less with the temperature than $\beta^{(1)}$, but analyzing the influence of temperature on the properties, such as the water activity, we have noticed that most influential parameter is $\beta^{(0)}$. Within the SIT approach, $\varepsilon_{0 \gamma}(\mathrm{M}, \mathrm{X})$ is the more influential parameter, which also changes more with the temperature.

Figure 1 shows a comparison of the calculated values and the experimental data at 298.15 K. Using the estimated Pitzer parameters we were able to calculate the osmotic coefficient of manganese nitrate solutions with good accuracy and the SIT model gives slight differences to the Pitzer results only for molalities higher than $8 \mathrm{~mol} \cdot \mathrm{kg}^{-1}$. The 


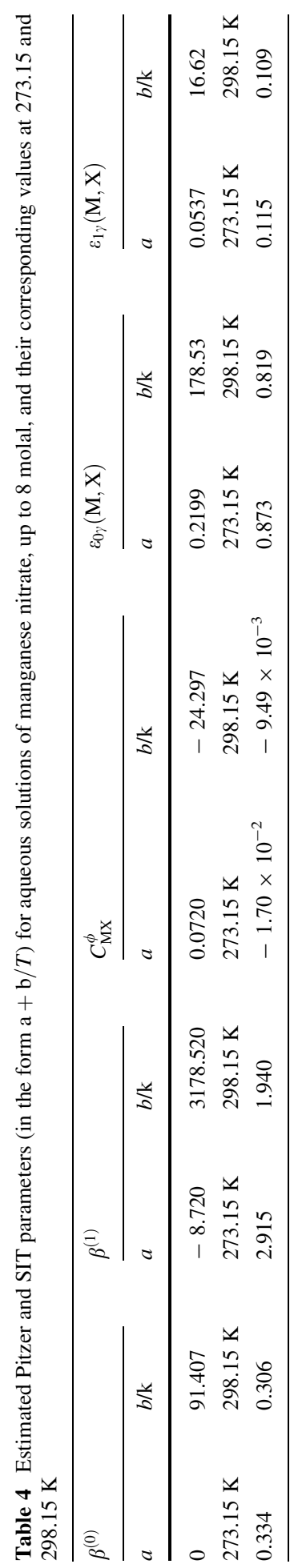


results obtained with both models emphasis the care that must be taken when extrapolating the value of thermodynamic properties in electrolyte systems. It should also be mentioned that the data from Ewing et al. [22] seems to be less accurate, and were not considered during correlation.

As shown in Fig. 2, both models are also able to represent the ice curve of manganese nitrate solutions, starting from very low temperatures up to the saturation limit of ice. The data from Arrad et al. [11] and Jones et al. [19] are in good agreement, but two data points from Jones et al. [19] are out of the general trend and were also not considered.

Another important analysis is the comparison between the calculated molality scale mean ionic activity coefficients of manganese nitrate at $298.15 \mathrm{~K}$. The obtained results are shown in Fig. 3. Concerning the calculations carried out by Sadowska and Libuś [10], the Pitzer parameters were claimed to be valid only up to 1.8 molal solutions, which was also the upper limit for the UNIQUAC model [11], and a polynomial expression was used to calculate them for higher molalities. However, we can point out that good agreement between both models studied in this work and the activity coefficients proposed by Sadowska and Libuś [10] is obtained up to $4 \mathrm{~mol} \cdot \mathrm{kg}^{-1}$.

The models and the parameter set found were also tested in the representation of some properties of the aqueous solutions of the investigated salt. The calculated water activities, at temperatures outside the range used for correlation are shown in Fig. 4. At low molalities, the water activities have identical shapes and the calculated values are very close to each other and to the experimental data. The Pitzer model differentiates more clearly the temperature effect on the behavior of manganese nitrate solutions at higher molalities, where Pitzer's model predicts a reduction in the water activity with increasing temperature and the data by Ewing et al. [22] presents the opposite change. On the other hand, Fig. 4 presents only a predictive curve for the SIT approach since almost identical water activities are obtained at both temperatures, which are also very close to the curve predicted by the Pitzer model at $303.15 \mathrm{~K}$.

Another important property was calculated extending the application limits of the Pitzer model. It is the experimental solubility product of manganese nitrate. The dissolution

Fig. 2 Ice curve for the manganese nitrate + water phase diagram with the experimental points superimposed

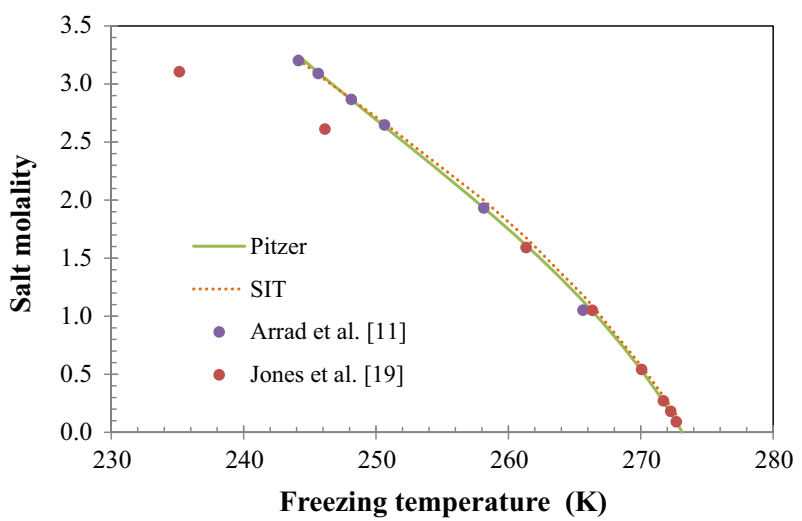


Fig. 3 Mean ionic molal activity coefficient of manganese nitrate in aqueous solutions at $298.15 \mathrm{~K}$ by the correlations developed in this work and that of Sadowska and Libuś [10]

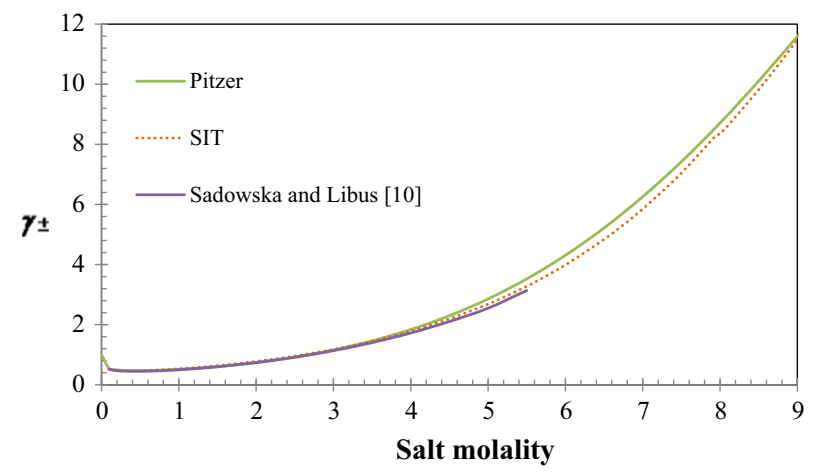

Fig. 4 Water activities of manganese nitrate solutions at selected temperatures calculated with the parameterized Pitzer model and SIT approach, compared with the experimental data by Ewing et al. [22] at 303.15 and $313.15 \mathrm{~K}$

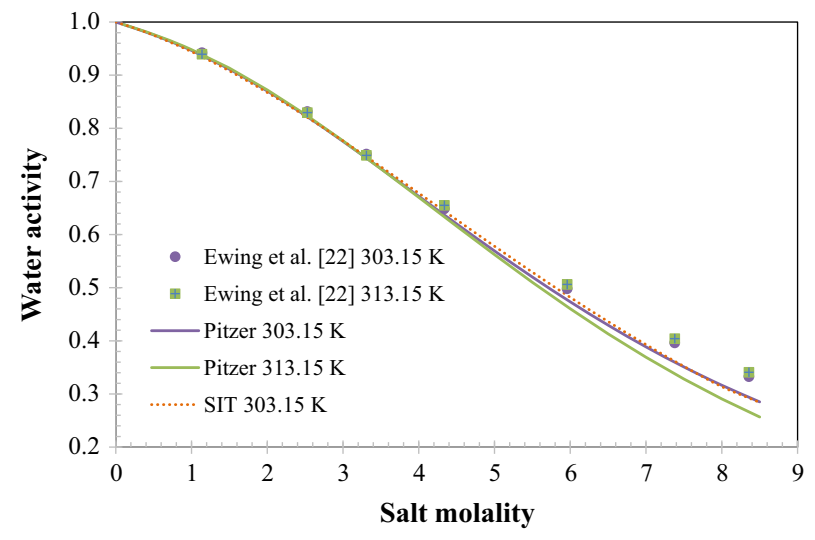

equation of manganese nitrate in water, and the expression of the solubility product $(K)$ are given by Eqs. 12 and 13, respectively.

$$
\begin{aligned}
& \mathrm{Mn}\left(\mathrm{NO}_{3}\right)_{2} \cdot 6 \mathrm{H}_{2} \mathrm{O}(\mathrm{s}) \rightleftharpoons \mathrm{Mn}^{2+}(\mathrm{aq})+2 \mathrm{NO}_{3}^{-}(\mathrm{aq})+6 \mathrm{H}_{2} \mathrm{O}(\mathrm{l}) \\
& K_{\mathrm{Mn}\left(\mathrm{NO}_{3}\right)_{2} \cdot 6 \mathrm{H}_{2} \mathrm{O}(\mathrm{s})}=a_{\mathrm{Mn}^{2+}(\mathrm{aq})} a_{\mathrm{NO}_{3}^{-}(\mathrm{aq})}^{2} a_{\mathrm{H}_{2} \mathrm{O}(\mathrm{l})}^{6}
\end{aligned}
$$

where $a_{i}$ stands for the activity of species $i$. Applying an iterative procedure, the solubility product of manganese nitrate hexahydrate was estimated (Eq. 14). To do this, the available solubility data for manganese nitrate hexahydrate (Table 3) and the Pitzer model developed in this work were used, obtaining:

$$
\ln K=1774.38+1.120 T-16341.48 / T-359.13 \ln T
$$

The solubility curve of manganese nitrate hexahydrate at low temperatures is in good agreement with experimental values (see Fig. 5) but deviations are noticeable above $290 \mathrm{~K}$, which corresponds to a $7 \mathrm{~mol} \cdot \mathrm{kg}^{-1}$. This deviation can be related to the limitation of Pitzer framework and the use of the molality scale to present concentrated aqueous solutions, but also to the great lack of experimental information to make the connection between the freezing point data and the solubility data at higher temperatures. A possible alternative is the use of the mole fraction based NPL Pitzer model [32], recently developed at National Physical Laboratory (United Kingdom), but involving a higher number of 
Fig. 5 Solubility of manganese nitrate hexahydrate in water between 250 and $300 \mathrm{~K}$

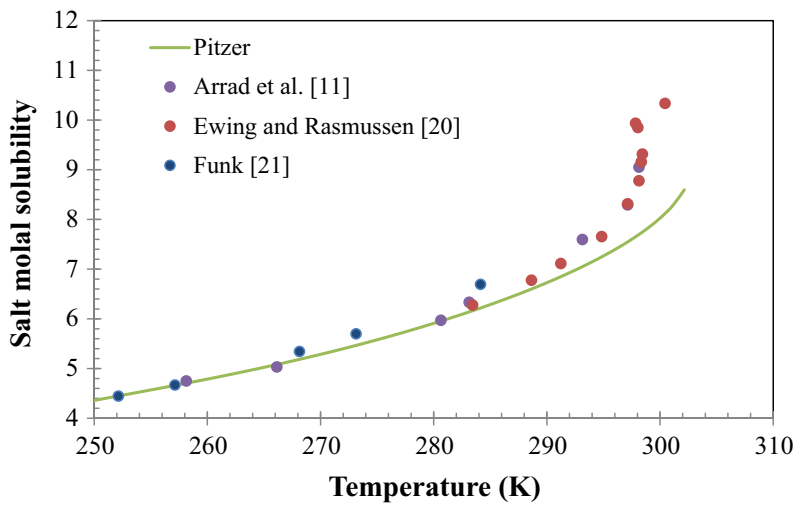

parameters, which is not recommended for such a small amount of available experimental information. At this point it is important to mention that Arrad et al. [11], using the extended UNIQUAC model, could represent the complete solubility diagram of manganese nitrate, estimating different solubility products for each of the solid phases. Yet, these authors failed in the description of the vapor-liquid equilibrium data available, showing the enormous difficulty of representing simultaneously both solid-liquid and vapor-liquid equilibrium with the same set of estimated parameters.

\section{Conclusions}

New water activity data for manganese nitrate solutions were measured. The available experimental data from the literature were critically analyzed before least squares fitting and parameterization of the system. The Pitzer model and SIT approach were used in order to calculate the water activities and mean activity coefficients of the dissolved salt, showing very comparable results.

In addition to the water activity data in homogeneous solutions, the available experimental freezing point depression data, and thus the heterogeneous solubility data from the literature, were also used to estimate the parameters of both models. The original Pitzer and SIT models predict well the aqueous solution properties in limited concentration ranges (around up to $7 \mathrm{~mol} \cdot \mathrm{kg}^{-1}$ ), including the osmotic coefficients and the water activity at various temperatures. An estimation of the solubility product of manganese(II) nitrate hexahydrate with the temperature is also proposed for the Pitzer model. The elaboration of this model is very important for the estimation of the activity coefficients of manganese nitrate, using a small number of adjustable parameters, with good representation of the various experimental quantities from vapor-liquid and solid-liquid equilibria.

Acknowledgements This work was developed in the scope of the projects POCI-01-0145-FEDER006984 - Associate Laboratory LSRE-LCM both funded by European Regional Development Fund (ERDF) through COMPETE2020-Programa Operacional Competitividade e Internacionalização (POCI)—and by national funds through FCT-Fundação para a Ciência e a Tecnologia. This work is also a result of project “AIProcMat@N2020_Advanced Industrial Processes and Materials for a Sustainable Northern Region of Portugal 2020", with the reference NORTE-01-0145-FEDER-000006, supported by Norte Portugal Regional Operational Programme (NORTE 2020), under the Portugal 2020 Partnership Agreement, through ERDF. 


\section{References}

1. Kim, H.T., Frederick, W.J.: Evaluation of Pitzer ion interaction parameters of aqueous electrolytes at $25{ }^{\circ}$ C. 1. Single salt parameters. J. Chem. Eng. Data 33, 177-184 (1988). https://doi.org/10.1021/ je00052a035

2. Robinson, R.A., Stokes, R.H.: Electrolyte Solutions, 2nd edn. Butterworths Scientific Publications, London (1959)

3. Rowland, D., May, P.M.: An investigation of Harned's rule for predicting the activity coefficients of strong aqueous electrolyte solution mixtures at $25^{\circ} \mathrm{C}$. J. Chem. Eng. Data 62, 310-327 (2017). https:// doi.org/10.1021/acs.jced.6b00651

4. May, P.M., Rowland, D., Hefter, G., Konigsberger, E.: A generic and updatable Pitzer characterization of aqueous binary electrolyte solutions at 1 bar and $25^{\circ} \mathrm{C}$. J. Chem. Eng. Data 56, 5066-5077 (2011). https://doi.org/10.1021/je2009329

5. Zemaitis, J.F., Clark, D.M., Rafal, M., Scrivner, N.C.: Handbook of Aqueous Electrolyte Thermodynamics. Theory and Application. AIChE, New York (1986)

6. Nezbeda, I., Moučka, F., Smith, W.R.: Recent progress in molecular simulation of aqueous electrolytes: force fields, chemical potentials and solubility. Mol. Phys. 114, 1665-1690 (2016). https://doi.org/10. 1080/00268976.2016.1165296

7. Moučka, F., Lísal Jr., M., Jirsák, J., Nezbeda, I., Smith, W.R.: Molecular simulation of aqueous electrolyte solubility. 2. Osmotic ensemble Monte Carlo methodology for free energy and solubility calculations and application to $\mathrm{NaCl}$. J. Phys. Chem. B 115, 7849-7861 (2011). https://doi.org/10.1021/ jp202054d

8. May, P.M., Rowland, D.: Thermodynamic modeling of aqueous electrolyte systems: current status. J. Chem. Eng. Data 62, 2481-2495 (2017). https://doi.org/10.1021/acs.jced.6b01055

9. Qiang, L., Sorensen, C.M., Klabunde, K.M., Hadjipanayis, G.C.: Aerosol spray pyrolysis synthesis of magnetic manganese ferrite particles. Aerosol Sci. Technol. 19, 453-467 (1993). https://doi.org/10. 1080/02786829308959651

10. Sadowska, T., Libuś, W.: Thermodynamic properties and solution equilibria of aqueous bivalent transition metal nitrates and magnesium nitrate. J. Solution Chem. 11, 457-468 (1982). https://doi.org/ 10.1007/BF00647108

11. Arrad, M., Kaddami, M., Maous, J., Thomsen, K.: Modeling the binary system $\mathrm{Mn}\left(\mathrm{NO}_{3}\right)_{2}-\mathrm{H}_{2} \mathrm{O}$ with the extended universal quasichemical (UNIQUAC) model. Fluid Phase Equilib. 397, 126-130 (2015). https://doi.org/10.1016/j.fluid.2015.04.008

12. Ciavatta, L.: The specific interaction theory in evaluating ionic equilibria. Ann. Chim. 70, 551-567 (1980)

13. Brønsted, J.N.: Studies on solubility IV. The principle of the specific interactions of ions. J. Am. Chem. Soc. 44, 877-898 (1922)

14. Guggenheim, E.A.: The specific thermodynamic properties of aqueous solutions of strong electrolytes. Philos. Mag. 19, 588-643 (1935)

15. Guggenheim, E.A., Turgeon, J.C.: Specific interaction of ions. Trans. Faraday Soc. 51, 747-761 (1955)

16. Scatchard, G.: Concentrated solutions of strong electrolytes. Chem. Rev. 19, 309-327 (1936)

17. Scatchard, G.: Equilibrium in Solutions. Surface and Colloid Chemistry. Harvard University Press, Massachusetts (1976)

18. Grenthe, I., Plyasunov, A.V., Spahiu, K.: Estimations of medium effects on thermodynamic data. In: I. Grenthe, I., I. Puigdomenech, I. (eds), Modelling in Aqueous Chemistry. Nuclear Energy Agency (1997) pp. 325-426

19. Jones, H.C., Getman, F.H., Bassett, H.P., McMaster, L.: Hydrates in Aqueous Solution: Evidence for the Existence of Hydrates in Solution. Their Approximate Composition and Certain Spectroscopic Investigation Bearing upon the Hydrate Problem. Carnegie Institution of Washington (1907)

20. Ewing, W.W., Rasmussen, H.E.: The temperature-composition relations of the binary system manganous nitrate-water. J. Am. Chem. Soc. 64, 1443-1445 (1942)

21. Funk, R.: Über die Löslichkeiteiniger Metallnitrate. Z. Anorg. Chem. 20, 393-418 (1899)

22. Ewing, W.W., Glick, C.F., Rasmussen, H.E.: Vapor pressure-temperature relations and heats of solution and dilution of the binary system manganous nitrate-water. J. Am. Chem. Soc. 64, 1445-1449 (1942)

23. Pinho, S.P: Water activity in aqueous amino acid solutions, with and without $\mathrm{KCl}$, at $298.15 \mathrm{~K}$. J. Chem. Eng. Data 53, 180-184 (2008). https://doi.org/10.1021/je700466s

24. Khan, I., Kurnia, K.A., Mutelet, F., Pinho, S.P., Coutinho, J.A.P.: Probing the interactions between ionic liquids and water: experimental and quantum chemical approach. J. Phys. Chem. B 118, 1848-1860 (2014). https://doi.org/10.1021/jp4113552 
25. Hamer, W.J., Wu, Y.C.: Osmotic coefficients and mean activity coefficients of uni-univalent electrolytes in water at $25^{\circ} \mathrm{C}$. J. Phys. Chem. Ref. Data 1, 1047-1099 (1972). https://doi.org/10.1063/1. 3253108

26. Archer, D.G.: Thermodynamic properties of the $\mathrm{NaBr}-\mathrm{H}_{2} \mathrm{O}$ System. J. Phys. Chem. Ref. Data 20, 509-555 (1991). https://doi.org/10.1063/1.555888

27. Jones, H.C., Getman, F.H.: Über das vorhandsein von hydraten in konzentrierten wässerigen lösungen. Z. Phys. Chem. 49, 385-455 (1904)

28. Pitzer, K.S.: Activity Coefficient in Electrolyte Solutions. CRC Press, Boca Raton (1991)

29. Akinfiev, N.N., Mironenko, N.N., Grant, S.A.: Thermodynamic properties of $\mathrm{NaCl}$ solutions at subzero temperatures. J. Solution Chem. 30, 1065-1080 (2001). https://doi.org/10.1023/A:1014445917207

30. Crea, F., Foti, C., de Stefano, C., Sammartano, S.: Sit parameters for 1:2 electrolytes and correlation with Pitzer coefficients. Ann. Chim. 97, 85-95 (2007)

31. Prausnitz, J.M., Lichtenthaler, R.N., Azevedo, E.G.: Molecular Thermodynamics of Fluid Phase Equilibria, 3rd edn. Prentice-Hall, New Jersey (1998)

32. Sippola, H., Kobylin, P., Taskinen, P.A.: Practical thermodynamic model for acidic sulfate solutions. In: Kvithyld, A., Meskers, C., Kirchain, R., Krumdick, G., Mishra, M., Reuter, M., Wang, C., Schlesinger, M., Gaustad, G., Lados, D., Spangenberger, J. (eds.) Proceeding REWAS 2013, pp. 155-166. Springer International Publishing, Berlin (2013). https://doi.org/10.1007/978-3-319-48763-2_17 